present in previous aspirates. No organisms were cultured from the fluid. In particular, there was no evidence of tubercle bacilli which had also been looked for on several previous occasions. The predominant cell type was lymphocytic and no malignant cells were found. A pleural biopsy was obtained at the time of aspiration with normal findings.

In view of the fact that the yellow discoloured nails and the longstanding oedema of the legs, suggested an abnormality of the lymphatic system, a lymphangiogram of the left arm was performed. This X-ray confirmed a defect by showing a marked hypoplasia of the lymphatic drainage. A similar hypoplasia of the lung's lymphatic system would account for the effusions following episodes of lung infection.

\section{Discussion}

Discolouration of the nails associated with lymphatic deficiency and lymphoedema was termed the 'yellow nail' syndrome by Samman \& Whyte (1964). They described thirteen cases, the oldest of whom was 65 at the time of presentation, and pointed out the characteristic features of the nails as exhibited in this case. The predominant involvement of the nails of the index finger on both hands is similar to that of the case reported by Dilley et al. (1968). This distribution is unexplained.

The further association of pleural effusions complicating the lymphoedema and yellow nails was described by Emerson (1966) and since then reported in such cases as that of D'Souza (1970). The theory of the development of the effusions is that respiratory infections may damage a previously adequate but hypoplastic lymphatic drainage system of the lung, so that it is no longer able to deal with the increased load following further incidents. In the limbs, it is known that persistent lymphoedema may develop following an infection or other episode which overloads a hypoplastic system which hiterto had been able to function adequately.

In a recent review of pulmonary manifestations of the yellow nail syndrome by Hiller, Rosenow \& Olsen (1972), the oldest case reported was a patient of 71 who had had chronic oedema of his lower extremities for 4-5 years, and yellow nails for 2 years before presenting with respiratory symptoms associated with a pleural effusion. The interest in this present case is in the even later age that the yellow nails developed, and the fact that it was not until the ninth decade that pleural effusions developed despite evidence to suggest lifelong lymphatic hypoplasia in the persistence of chronic oedema of the legs since childhood.

\section{Acknowledgments}

We are grateful to Dr F. Ashton for permission to publish details of this case and Dr M. W. Stannard for performing the lymphangiogram.

\section{References}

Dilley, J.J., Kierland, R.R., Randall, R.V. \& Shick, R.H. (1968) Primary lymphoedema associated with yellow nails and pleural effusions. Journal of the American Medical Assoctation, 204, 670.

D'SouzA, M.F. (1970) Generalized lymphoedema with yellow nails, pleural effusions and macroglobulinaemia. Proceedings of the Royal Society of Medicine, 63, 456.

EMERSON, P.A. (1966) Yellow nails, lymphoedema and pleural effusions. Thorax, 21, 247.

Hiller, E., Rosenow, E.C. \& Olsen, A.M. (1972) Pulmonary. manifestations of the yellow nail syndrome. Chest, 61, 452

Samman, P.D. \& White, W.F. (1964) The 'yellow nail' syndrome. British Journal of Dermatology, 76, 153.

Postgraduate Medical Journal (May 1973) 49, 365-367.

\title{
The use of intra-arterial Urokinase in a case of recurrent arterial occlusion
}

\author{
B. J. BOUCHER \\ M.D., M.R.C.P.
}

\author{
E. M. CONNOLLY \\ M.B., B.Ch., B.A.O.
}

\section{S. C. FARROW \\ M.A., M.R.C.P.(U.K.) \\ Departments of Medicine and Pathology, London Hospital E.1}

\section{Summary}

The present case report describes the use of intraarterial Urokinase in an occlusive episode involving the right radial and ulnar arteries. Details of the case history are given and the choice of thrombolytic therapy, plus its route of administration are discussed.

\section{Introduction}

The use of intravenous lytic therapeutic agents has been well defined in the treatment of occlusive venous thrombosis (Kakkar et al., 1969; Robertson, Nilsson \& Nylander, 1969), although there is no ideal regime for their use (Study Group, 1970). Streptokinase has been widely used in episodes of acute arterial thrombo-occlusive disease (Polidwoda et al., 1969; Martin, Schoop \& Zeitler, 1970; Amery et al., 1970) and occasionally it has been given intraarterially by local perfusion (McNicol et al., 1963; 
Bose, Brose \& Hartley, 1969). The human fibrinolytic activator, Urokinase, has also been used intraarterially, but only infrequently (Tsapogas, 1964) and not in the upper limb, although successful lysis of arterial thrombi in the left arm has been achieved with streptokinase (Bose et al., 1969).

\section{Case report}

J.M., aged 47 at death.

Aged 43 and 46 transient tingling of fingers and toes was noted.

Aged 46 and 47-two transient episodes of unsteadiness with diplopia, following the second of which he was admitted to hospital and reduced pulse and blood pressure were noted in the left arm (BP $120 / 80$ left and 140/90 right) with a left subclavian bruit. Acute ischaemia developed in the fingers of the left hand and angiography showed left subclavian narrowing proximal to the origin of the left vertebral artery. Left subclavian endarterectomy and left cervical sympathectomy were performed, followed $8 \mathrm{hr}$ later by left subclavian thrombectomy. Despite initial recovery and adequate anticoagulation with heparin and then Warfarin, acute ischaemic episodes led, during the next 3 months, to successive amputations of the fingers of the left hand followed by total amputation of the left hand above the wrist. When ischaemic lesions led to amputation of the toes of the left foot the diagnosis was reviewed. No vasculitis had been found, and an atrial myxoma was excluded by ultrasonic and angiocardiographic examinations. There was also no positive evidence of bacterial endocarditis. Clotting and fibrinolytic mechanisms were not examined in detail. During the next 4 months whilst on adequate doses of Warfarin and despite right cervical sympathectomy and a course of $\alpha$ adrenergic blocking agents, the fingers and distal phalanx of the thumb on the right hand and all the toes of the right foot were amputated successively because of episodes of further acute arterial occlusion. Although he was a heavy smoker there was no evidence of Buerger's disease.

Polyarteritis nodosa was reported on histological examination at this time and prednisone therapy (10 mg t.d.s.) was commenced. The patient was transferred from surgical care for an attempt at rehabilitation. A month later, whilst prednisone was being reduced (since further histological review had failed to confirm polyarteritis nodosa), the right radial and ulnar arteries thrombosed from the wrist to above the elbow over a period of $12 \mathrm{hr}$. The extent of the occlusion was confirmed by Doppler ultrasonic detectors. A Seldinger arterial catheter was inserted into the right subclavian artery, and 300,000 units of Urokinase was given in $50 \mathrm{ml}$ of normal saline over $2 \mathrm{hr}$ using a constant infusion pump (Anderson et al., 1961). The brachial and right radial pulses returned clinically within $12 \mathrm{hr}$ and normal flow was confirmed using ultrasound. Twelve hours later serum plas- $\frac{\mathbb{\Phi}}{2}$ minogen was measured and found to be within $\stackrel{\complement}{c}$ normal limits. This allowed anticoagulation to be continued with Arvin, which was given initially at a dosage of 2 units $/ \mathrm{kg}$ in $200 \mathrm{ml}$ of normal saline over $6 \mathrm{hr}$ by constant intravenous infusion, followed by 2 units $/ \mathrm{kg}$ in $20 \mathrm{ml}$ of normal saline given intra- $\frac{\overline{\bar{c}}}{\frac{\mathrm{O}}{2}}$ venously twice daily for 5 days. Estimations were $\stackrel{\mathbb{Q}}{\varrho}$ taken daily of plasma fibrinogen and clot formation, and a state of circulating fibrinogen depletion was $\vec{\sim}$ maintained. On the same day that Arvin therapy? began, oral administration of fibrinolytic therapy $\vec{\omega}$ was started with phenformin (50 mg b.d.) and ethyl- $\stackrel{\circ}{\circ}$ oestrenol ( $2 \mathrm{mg}$ q.d.s.). Three weeks later the patiento became confused and following a small melaena he 3 . died suddenly, despite adequate blood transfusion.

Necropsy revealed widespread embolization from if aseptic thrombotic vegetations on the mitral valve. The valve itself was normal with no underlying $\dot{\sigma}^{\circ}$ rheumatic heart disease. There were scattered foci of ${ }^{\circlearrowleft}$ fibrous replacement of the myocardium. The aorta showed marked atheroma. All the main arteries were normal with the exception of the left subclavian, which $1 \mathrm{~cm}$ from its origin narrowed for a distance of $4 \mathrm{~cm}$ to a solid cord $2 \mathrm{~mm}$ in diameter. The $\vec{\varphi}$ brachial, radial, femoral and dorsalis pedis arterie $\omega$ on each side appeared normal. Histological examin tion revealed atheromatous plaques in both brachi⿳⺈ and right radial arteries. The right dorsalis pedis artery was occluded by organized thrombus.

There was an aseptic splenic infarct and evidence $\stackrel{\varrho}{\mathbb{Q}}$ of fibrin occlusion of scattered interlobular arteries $\underset{\vec{P}}{\vec{P}}$ in the kidney. There were organizing thrombi in the $\frac{3}{3}$ meningeal vessels with an area of softening in the right frontal lobe.

Other organs were normal with the exception of an haemorrhagic purulent pneumonia of both lower 3 . lobes. There was no evidence of gastro-intestinal haemorrhage.

Sections from various amputation specimens and $\stackrel{0}{\circ}$ extensive necropsy study failed to show any arteritis. The constant abnormality was small arteries occluded by thrombus.

\section{Discussion}

The reason for this man's peripheral arterial occlusions was never adequately clarified in life $\tilde{N}$ although the clinical course and necropsy findings $\underset{\omega}{ }$ suggest that he suffered repeated embolization to small and large arteries from aseptic thrombotico vegetations on the mitral valve with some local arterial thrombosis.

The continued episodes of arterial occlusion over $\underset{T}{T}$ a period of 9 months despite adequate anticoagula- $\frac{\vec{D}}{\bar{D}}$ tion suggests that he may have had a defect in $\stackrel{\mathbb{Q}}{\mathbb{P}}$ fibrinolysis. When the final arterial block in the right $\stackrel{\mathbb{Q}}{\varrho}$ 
arm developed it was felt that fibrinolytic therapy might be effective whether the occlusion was thrombotic or embolic.

In view of the reports of successful use of Urokinase in local arterial occlusion (Tsapogas, 1964) and the low incidence of reactions (Hansen et al., 1961) when compared with streptokinase (Amery et al., 1970; Hume, 1970; Verstraete, 1971) Urokinase was chosen. It was, however, in short supply and in order to achieve maximum local effect it was infused intra-arterially. Intra-arterial catheterization may be associated with an increased risk of arterial spasm but it was thought that the patient's previous cervical sympathectomy would help minimize this risk. Nevertheless, the patient's digitless state, his absolute refusal to contemplate further amputation and the threatened loss of his only remaining grip mechanism reinforced the decision to use Urokinase locally. It is significant that this episode, treated with Urokinase, was the only overt episode of arterial occlusion to be followed by recovery without further amputation, and indeed it was followed by stump healing in the 2-3 weeks before he died. We consider that local Urokinase was effective in restoring the local circulation. The decision to maintain anticoagulation by defibrination with Arvin (Ashford, Ross \& Southgate, 1968; Bell, Pitney \& Goodwin, 1968; Sharp et al., 1968; Kakker et al., 1969) was made because previous arterial occlusion had developed whilst on heparin and on Warfarin and because controlled Arvin therapy carries a lower risk of serious bleeding from normal tissues than do other anticoagulation regimens. However, both the defibrination and the steroid therapy may well have contributed to the subsequent gut bleeding although the likely cause of death was from widespread peripheral emboli-with involvement of meningeal vessels. There was a terminal broncho-pneumonia.

Efforts to improve fibrinolytic mechanisms with phenformin and ethyloestrenol were made too late to have contributed either to his gut bleeding or to the maintenance of patency of his remaining arterial circulation (Fearnley, Chakrabarti \& Hocking, 1967; Chakrabarti et al., 1968; Brown et al., 1971).

In conclusion, this patient's case history demonstrates that intra-arterial Urokinase can be a useful adjunct to therapy in the difficult problem of recurrent arterial occlusion.

\section{Acknowledgments}

We are grateful to $\mathrm{Mr}$ D. G. A. Eadie for referring this patient. We thank Mr P. Parker of Leo Laboratories Ltd for the generous gift of the Urokinase and for useful discussions, Dr P. T. Flute for plasminogen estimations, Professor F. A. Robinson and Twyford Laboratories for the gift of Arvin and for advice on its use. We also thank Dr T. M. Savege for inserting the arterial cannula and Dr C. M. Oakley, Dr D. W. Vere, Professor I. Doniach, Dr J. W. Landells and Dr J. A. F. McLean for helpful discussion.

\section{References}

Amery, A., Deloof, W., Vermylen, J. \& Verstraete, M. (1970) Outcome of recent thromboembolic occlusions of limb arteries treated with streptokinase. British Medical Journal, 4, 639.

Anderson, J., Parson, V., Baker, L. W. \& Dudley, H.A.F. (1961) A medical metering pump. Lancet, i, 646.

Ashrord, A., Ross, J.W. \& Southgate, P. (1968) Pharmacology and toxicology of a defibrinating substance from Malayan pit viper venom. Lancet, i, 486.

Bell, W. R., Pitney, W.R. \& Goodwin, J.F. (1968) Therapeutic defibrination in the treatment of thrombotic disease. Lancet, i, 490.

Bose, A., Brose, S.S. \& Hartley, G. (1969) Experiences with intra-arterial Streptokinase perfusion in the treatment of acute arterial thrombosis. Journal of Clinical Pathology, 22, 374.

Brown, I.K., Haggart, B., Murray, G.H., Downie, R.J., LitTler, J., RobB, P.M. \& SANTer, G.J. (1971) Pharmacological stimulation of fibrinolytic activity in the surgical patient. Lancet, i, 774.

Chakrabarti, R., Hocking, E.D., Fearnley, G.R., Mann, R.D., Attwell, T.N. \& Jackson, D. (1968) Fibrinolytic activity and coronary-artery disease. Lancet, i, 987.

Fearnley, G.R., Chakrabarti, R. \& Hocking, E.D. (1967) Fibrinolytic effects of diguanides plus ethyloestrenol in occlusive vascular disease. Lancet, ii, 1008.

Hansen, P.F., Jørgensen, M.D., KJeldgaARd, N.O. \& Ploug, J. (1961) Urokinase-activator of plasminogen from human urine. Angiology, 12, 8.

Hume, M., Gurewich, V., Thomas, D.P. \& Dealy, J.B. (1970) Streptokinase for chronic arterial occlusive disease. Archives of Surgery, 101, 653.

KakKar, V.V., Howe, C.T., Laws, J.W. \& FlanC, C. (1969) Late results of treatment of deep vein thrombosis. British Medical Journal, 1, 810.

Kakkar, V.V., Flanc, C., Howe, C.T., O'Shea, M. \& FLUTE, P.T. (1969) Treatment of deep vein thrombosis. A trial of heparin streptokinase and Arvin. British Medical Journal, 1, 806.

Martin, M., Schoop, W. \& Zeitler, E. (1970) Streptokinase in chronic arterial occlusive disease. Journal of the American Medical Association, 211, 1169.

MCNicol, G.P., Reid, W., Bain, W.H. \& Douglas, A.S. (1963) Treatment of peripheral arterial occlusion by streptokinase perfusion. British Medical Journal, 1, 1508.

Poliwoda, H., Alexander, K., Buhl, V., Holsten, D. \& WAGNER, H.H. (1969) Treatment of chronic arterial occlusions with streptokinase. New England Journal of Medicine, 280, 689.

Robertson, B.R., Nilsson, I.M. \& Nylander, G. (1969) Value of streptokinase and heparin in treatment of acute deep vein thrombosis. Journal of Clinical Pathology, 22, 372.

Sharp, A.A., Warren, B.A., Paxton, A.M. \& Allington, M.J. (1968) Anticoagulant therapy with a purified fraction of Malayan pit viper venom. Lancet, i, 493.

Study Group. (1970) Urokinase pulmonary embolism trial. Journal of American Medical Association, 214, 2163.

Tsapogas, M.J. (1964) The role of fibrinolysis in the treatment of arterial thrombosis: Experimental and clinical aspects. Annals of the Royal College of Surgeons, 34, 293.

Verstraete, M., Vermylen, J. \& Benedetta, M. (1971) The effect of streptokinase infusion on chronic arterial occlusions and stenoses. Annals of Internal Medicine, 74, 3, 377. 